Table 1. Presence of psychiatric diagnoses in patients with SLE and neuropsychiatric symptoms

\begin{tabular}{|c|c|c|c|}
\hline & $\begin{array}{c}\text { All } \\
\text { patients } \\
(n=371)\end{array}$ & $\begin{array}{c}\text { Minor/ } \\
\text { non-NPSLE } \\
(\mathrm{n}=\mathbf{2 6 1})\end{array}$ & $\begin{array}{c}\text { Major } \\
\text { NPSLE } \\
(n=110)\end{array}$ \\
\hline \multicolumn{4}{|l|}{ DSM V diagnosis, $\mathrm{n}(\%)$} \\
\hline Neurodevelopmental disorder & $5(1)$ & $2(1)$ & $3(2)$ \\
\hline Schizophrenia Spectrum and Other Psychotic Disorders & $16(4)$ & $10(4)$ & $6(6)$ \\
\hline Bipolar and related disorders & $7(2)$ & $5(2)$ & $2(2)$ \\
\hline Depressive disorders & $84(23)$ & $68(26)$ & $16(15)$ \\
\hline Anxiety disorders & $17(5)$ & $15(6)$ & $2(2)$ \\
\hline Obsessive-Compulsive and Related Disorders & $1(0)$ & $1(0)$ & $0(0)$ \\
\hline Trauma- and Stressor-Related Disorders & $16(4)$ & $12(5)$ & $4(3)$ \\
\hline Dissociative Disorders & $2(1)$ & $2(1)$ & $0(0)$ \\
\hline Somatic Symptom and Related Disorders & $1(0)$ & $1(0)$ & $0(0)$ \\
\hline Feeding and Eating Disorders & $0(0)$ & $1(0)$ & $0(0)$ \\
\hline Elimination Disorders & $0(0)$ & $0(0)$ & $0(0)$ \\
\hline Sleep-wake disorders & $2(1)$ & $2(1)$ & $0(0)$ \\
\hline Sexual dysfunctions & $0(0)$ & $0(0)$ & $0(0)$ \\
\hline Gender dysphoria & $0(0)$ & $0(0)$ & $0(0)$ \\
\hline Disruptive, Impulse-Control, and Conduct Disorder & $0(0)$ & $0(0)$ & $0(0)$ \\
\hline Substance-related and addictive disorders & $9(2)$ & $8(3)$ & $1(1)$ \\
\hline Cognitive dysfunction & $154(42)$ & $95(36)$ & $59(54)$ \\
\hline Personality disorders & $10(3)$ & $9(3)$ & $1(1)$ \\
\hline Paraphilic disorders & $0(0)$ & $0(0)$ & $0(0)$ \\
\hline Other mental disorders & $12(3)$ & $7(3)$ & $5(5)$ \\
\hline $\begin{array}{l}\text { Medication-Induced Movement Disorders and Other } \\
\text { Adverse Effects of Medication }\end{array}$ & $0(0)$ & $0(0)$ & $0(0)$ \\
\hline Unknown & $3(1)$ & $3(1)$ & $0(0)$ \\
\hline
\end{tabular}

NPSLE = neuropsychiatric systemic lupus erythematosus.

Disclosure of Interests: None declared

DOI: 10.1136/annrheumdis-2021-eular.423

\section{POS0709 LUPUS FOG IS NOT DISSOCIATIVE FOG}

R. Monahan ${ }^{1}$, A. Blonk ${ }^{2}$, H. Middelkoop ${ }^{3}$, M. Kloppenburg ${ }^{1,4}$, T. Huizinga ${ }^{1}$, N. Van der Wee ${ }^{2}$, G. M. Steup-Beekman ${ }^{1} .^{1}$ Leiden University Medical Center (LUMC), Department of Rheumatology, Leiden, Netherlands; ${ }^{2}$ Leiden University Medical Center, Department of Psychiatry, Leiden, Netherlands; ${ }^{3}$ Leiden University Medical Center, Department of Neurology, Leiden, Netherlands; ${ }^{4}$ Leiden University Medical Center, Department of Clinical Epidemiology, Leiden, Netherlands

Background: The presence of a 'fog' is frequently reported by patients with systemic lupus erythematosus (SLE). However, little is known about this lupus fog: it is thought to be a result of cognitive dysfunction, but fogs can also be the result of dissociation. The Dissociative Experience Scale-II (DES) is a standardized tool to study dissociation. In the general adult population, scores range from 4.4-14. ${ }^{1-3}$ Objectives: We aimed to study the prevalence of dissociative symptoms including dissociative fog in patients with SLE and neuropsychiatric symptoms.

Methods: Patients visiting the tertiary referral center for neuropsychiatric systemic lupus erythematosus (NPSLE) of the LUMC between 2007-2019 were included. All patients underwent a standardized multidisciplinary assessment. Patients were classified as NPSLE if neuropsychiatric symptoms were attributed to SLE and immunosuppressive or anticoagulant therapy was initiated, otherwise patients were classified as minor/non-NPSLE. Dissociation was studied using the DES. The DES separates different types of dissociative symptoms: amnesia, absorption/imagination and derealization/depersonalization. It also contains one question regarding evaluating the presence of a dissociative fog: "Some people sometimes feel as if they are looking at the world through a fog, so that people and objects appear far away or unclear". All statements $(n=28)$ regarding dissociative symptoms are rated from 'none of the time' to 'all of the time' (0-100\%); scores $>25$ are considered abnormal. A multiple regression analysis (MRA) were performed to compare dissociation in patients with and without NPSLE. DES results are presented as median (range) and MRA as odds ratio (OR) and $95 \%$ confidence interval $(\mathrm{Cl})$.

Results: DES questionnaires were available for 337 patients, of which 97 had the diagnosis NPSLE (29\%). Mean age in patients with NPSLE was $41 \pm 13$ years and $84 \%$ was female. In minor/non-NPSLE, median age was $44 \pm 14$ years and $87 \%$ was female.

Median dissociation was 7 (0-75) and did not differ between patients with minor/ non-NPSLE and NPSLE (OR: $1.0(95 \% \mathrm{Cl}:-0.9 ; 1.1))$. The most common type of dissociation was absorption/imagination (median: 12, range 0-75) and depersonalization/derealization was infrequent (median: 1 , range $0-84$ ). 43 patients $(13 \%)$ had an abnormal score (>25) on the dissociative fog question.

Conclusion: Dissociative symptoms are within normal range in patients with SLE and neuropsychiatric symptoms, regardless of underlying etiology. Dissociative fog seems uncommon and therefore lupus fog is most likely not the result of dissociation.

\section{REFERENCES:}

[1] Bernstein EM and Putnam FW. Development, reliability, and validity of a dissociation scale. J Nerv Ment Dis 1986; 174: 727-735. 1986/12/01. DOI: 10.1097/00005053-198612000-00004.

[2] Maaranen P, Tanskanen A, Honkalampi K, et al. Factors associated with pathological dissociation in the general population. Aust N Z J Psychiatry 2005; 39: 387-394. 2005/04/30. DOI: 10.1080/j.1440-1614.2005.01586.x.

[3] van IJzendoorn $\mathrm{MH}$ and Schuengel C. The measurement of dissociation in normal and clinical populations: Meta-analytic validation of the Dissociative Experiences Scale (DES). Clinical Psychology Review 1996; 16: 365-382. DOI: 10.1016/0272-7358(96)00006-2.

Table 1. Presence of dissociation in patients with SLE and neuropsychiatric symptoms

\begin{tabular}{lccc}
\hline & $\begin{array}{c}\text { Total cohort } \\
(\mathrm{n}=337)\end{array}$ & $\begin{array}{c}\text { Minor/non-NPSLE } \\
(\mathrm{n}=240)\end{array}$ & $\begin{array}{c}\text { NPSLE } \\
(\mathrm{n}=97)\end{array}$ \\
\hline DES (median, range) & & & \\
Total questionnaire & $7(0-75)$ & $8(0-66)$ & $6(0-75)$ \\
Amnesia & $5(0-76)$ & $5(0-68)$ & $4(0-76)$ \\
Absorption/imagination & $12(0-75)$ & $13(0-75)$ & $10(0-73)$ \\
$\begin{array}{l}\text { Depersonalization/derealization } \\
\text { Dissociative fog* }\end{array}$ & $1(0-84)$ & $1(0-73)$ & $1(0-84)$ \\
& $0(0-100)$ & $0(0-100)$ & $0(0-100)$
\end{tabular}

$D E S$ = Dissociative Experience Scale NPSLE = neuropsychiatric systemic lupus erythematosus. ${ }^{*}$ Dissociative fog is question 28 of the DES-II

Disclosure of Interests: None declared

DOI: 10.1136/annrheumdis-2021-eular.424

\section{POS0710 ANALYSIS OF 5-YEAR HOSPITALIZATION DATA OF PATIENTS WITH SYSTEMIC LUPUS ERYTHEMATOSUS: DAMAGE IS A RISK FACTOR FOR FREQUENT AND LONGER STAYS}

C. Cetin ${ }^{1}$, M. G. Can ${ }^{2}$, S. Oztaskin ${ }^{2}$, Y. Yalçınkaya ${ }^{1}$, A. Gül ${ }^{1}$, M. Inanc ${ }^{1}$, B. ArtimEsen ${ }^{1}{ }^{1}$ Istanbul Faculty of Medicine, Rheumatology, Istanbul, Turkey; ${ }^{2}$ Istanbul Faculty of Medicine, Internal Medicine, İstanbul, Turkey

Background: The rates of hospitalization in patients with SLE is around 10\% per year. ${ }^{1}$

Objectives: In this study, we aimed to examine the hospitalization data of patients with SLE in the last 5 years at our center and determine the factors that affect hospitalization.

Methods: Hospitalization data of patients with SLE (2012 SLICC classification) admitted to our rheumatology ward between January 2015 and 2020 were analyzed. Cumulative clinical and laboratory findings were retrieved from the existing SLE database and revised. SLICC SLE damage index (SDI), and the disease activity at admission were determined (SLEDAI-2K).

Results: Eighty-six \% ( $n=138)$ of 161 hospitalized patients were female. The mean age of the patients was $38 \pm 13$ years whilst mean duration of disease was $97.3 \pm 96.9$ months. Thirty-eight\% of the patients were hospitalized more than once and the mean number of hospitalizations was $1.8 \pm 1.5$ The mean hospitalization duration covering all stays for each patient was $25 \pm 27$ days. Active disease followed by infection and damage-related complications ranked the first three among all causes of hospitalization.

Compared to patients hospitalized for active disease or other reasons, patients hospitalized for infection had a significantly higher number of readmissions $(p<0.05)$ and their total duration of hospitalization was longer $(p<0.01)$. Duration of disease was significantly shorter in patients hospitalized for active disease compared to patients hospitalized for infection and damage related causes $(p<0.05)$.

The frequency of patients with damage and the mean SDI score was significantly lower in the group with active disease $(68 \%$ and $1.9 \pm 2)$ compared to patients hospitalized for infection $(90 \%$ and $2.7 \pm 1.6)$ and other causes $(96 \%$ and $3 \pm 1.7$ ) ( $<<0.05$ for both). Distribution of damage according to organ/systems is presented in Graph 1. Highest frequency of damage was detected in the cardiovascular $(30 \%)$, followed by neuropsychiatric $(26.7 \%)$, renal $(23 \%)$, pulmonary $(23 \%)$ and musculoskeletal $(20.5 \%)$ domains. A positive correlation was found between the mean SDI score and duration of hospitalization $(r=0.551, p<0.001)$ as well as the number of hospitalizations $(r=0.393, p<0.001)$. Regarding disease activity at the time of admission, the mean score of patients hospitalized for active disease was $11.0 \pm 6.1$ whilst was $3.2 \pm 2.8$ in patients hospitalized for infection and $2.9 \pm 3.3$ in patients hospitalized for other reasons $(\mathbf{p}<0.001)$. Renal active disease was the most common (44\%), followed by hematological (34.8\%), articular $(21.7 \%)$ and mucocutaneous $(21 \%)$ activity. Ten\% of the patients all of whom had damage were admitted to intensive care unit (ICU). Total hospitalization duration $(p=0.012)$, mean SDI $(p=0.008)$, antiphospholipid syndrome $(p=0.033)$, lupus anticoagulant $(p=0.010)$, thrombocytopenia $(p=0.015)$, 